\title{
Judicial Review as a Response to Political Posturing
}

\section{Citation}

Matthew Stephenson \& Justin Fox, Judicial Review as a Response to Political Posturing, 105 Am. Pol. Sci. Rev. 397 (2011).

\section{Published Version}

http://dx.doi.org.ezp-prod1.hul.harvard.edu/10.1017/S0003055411000116

\section{Permanent link}

http://nrs.harvard.edu/urn-3:HUL.InstRepos:10814613

\section{Terms of Use}

This article was downloaded from Harvard University's DASH repository, and is made available under the terms and conditions applicable to Open Access Policy Articles, as set forth at http:// nrs.harvard.edu/urn-3:HUL.InstRepos:dash.current.terms-of-use\#OAP

\section{Share Your Story}

The Harvard community has made this article openly available.

Please share how this access benefits you. Submit a story.

Accessibility 


\title{
Judicial Review as a Response to Political Posturing
}

\author{
JUSTIN FOX Yale University \\ MATTHEW C. STEPHENSON Harvard University
}

$W$

e use an agency model to analyze the impact of judicial review on the incentives of elected leaders to "posture" by enacting bold but ill-advised policies. We find that judicial review may exacerbate posturing by rescuing leaders from the consequences of unwise policies, but may also discourage posturing by alerting voters to unjustified government action. We further find that judges will defer to the decision of elected leaders unless posturing is sufficiently likely. We then show how judicial review affects voter welfare, both through its effect on policy choice and through its effect on the efficacy of the electoral process in selecting leaders. We also analyze how the desirability of judicial review is affected by characteristics of the leaders and the judges.

W hat is the appropriate role for judicial review in a democracy? This question has been a central preoccupation of American constitutional theory (Friedman 2002), and has assumed increasing salience internationally as the power and influence of courts around the world has grown (Hirschl 2004). Many have defended judicial review as a way to reduce or correct systematic failures in legislative and executive decision making - thereby reducing the divergence between actual policy choices and those that would prevail in an ideally functioning representative democracy. Appropriately designed judicial review, on this view, can be justified on democratic grounds, even if judicial review is not itself a democratic institution. Critics, however, argue that judicial review tends to exacerbate rather than ameliorate the pathologies of representative democracy, and that the costs of judicial review typically exceed whatever benefits it may have.

We analyze judicial review as a potential response to a particular problem: The incentive of elected officials to "posture" by taking bold but unwarranted action in response to a perceived emergency in order to appear competent to the voters. We begin by providing a brief overview of this potential problem and the debates over whether judicial review is an appropriate remedy. We then turn to presenting a model of political agency, without judicial review, to show how this sort of posturing may arise. We then modify this model by introducing judicial review.

We show that judicial review has two main effects on the frequency of posturing. First, judicial review

We are grateful to Gabriella Blum, Rachel Brewster, Ethan Bueno de Mesquita, Glenn Cohen, Barry Friedman, Jim Greiner, Matias Iaryczower, Leslie Johns, Dimitri Landa, Adriaan Lanni, Gilat Levy, Andrew Martin, Judkins Mathews, Nolan McCarty, Mathew McCubbins, Minor Myers, Eric Posner, Ben Roin, Frances Rosenbluth, Ben Sachs, Ken Shepsle, Kenneth Shotts, Jed Shugerman, Jeffrey Staton, Bill Stuntz, Richard Van Weelden, Adrian Vermeule, Abby Wood, Kathy Zeiler, and Aaron Zelinksy. We also thank seminar participants at Columbia, Emory, LSE, Notre Dame, MIT, Harvard, Northwestern, Stanford, UCLA, the University of Chicago, and Yale for helpful comments.

Justin Fox is Assistant Professor, Department of Political Science, Yale University, ISPS, P.O. Box 208209, New Haven, CT 06520. (justin.fox@yale.edu).

Matthew C. Stephenson is Professor of Law, Harvard Law School, Harvard University, Griswold 509, Cambridge, MA 02138. (mstephen@law.harvard.edu). may rescue elected officials from the consequences of ill-advised policies, and this "bailout effect" increases posturing; second, judicial approval or disapproval of a policy may affect public opinion of the government that enacted it, and this "legitimation effect" can cut in the opposite direction-decreasing posturing. We next show that a rational judge's review strategy depends on the prevalence of posturing. If posturing is sufficiently rare, then the judge would defer to the elected leader, whereas if posturing is sufficiently common, the judge would flatly prohibit the problematic government action; judges rely on their own judgment only for "intermediate" levels of posturing. We then combine these partial-equilibrium analyses to assess the net impact of judicial review.

Finally, we turn to normative considerations, focusing on how judicial review affects voter welfare both through its effect on policy choice and through its effect on the efficacy of the electoral process in selecting good leaders. Our welfare analysis illustrates conditions under which judicial review serves majoritarian interests - and thereby arguably increases the "democratic" character of political outcomes, despite the nondemocratic nature of judicial review itself-and also conditions under which judicial review, even by well-motivated judges, can make voters worse off. We also consider how the desirability of judicial review is affected by characteristics of the leaders and the judges. Our results here are sometimes surprising. For example, increasing judicial competence can sometimes make judicial review less socially desirable. A supplemental online Appendix (available at http://www.journals.cambridge.org/psr2011007) contains proofs of all formal propositions in the text.

\section{JUDICIAL REVIEW AS A RESPONSE TO POSTURING: AN OVERVIEW}

The selection of leaders through regular democratic elections serves many purposes. Among these, perhaps the most important is the (potential) amelioration of the principal-agent problem inherent in any system of political representation because elections allow voters both to "select good types" (competent leaders who share the voters' preferences) and to "sanction poor performance" (Fearon 1999). Elections, however, are 
not a perfect solution to the political agency problem and may sometimes have perverse effects: Concerns about reelection can distort the incentives of political leaders, causing them to adopt policies that improve the leaders' short-term popularity, but that are actually worse for a majority of voters. For example, an elected leader may "pander" by adopting whatever policy the voters believe ex ante is more likely to be correct, even though the leader's own information suggests otherwise (Canes-Wrone, Herron, and Shotts 2001). Thus, elected leaders may be too timid if they are concerned that unexpected policy initiatives will be perceived as a sign of incompetence or bias. In other contexts, electoral pressures may have precisely the opposite perverse effect: A leader may have an incentive to "posture" by taking some bold, dramatic action in order to appear competent to voters, even though the leader is insufficiently confident that such dramatic action is warranted. ${ }^{1}$ Such posturing might be especially likely when the polity is confronted with a perceived emergency, such as an economic or national security crisis. In such cases, leaders face tremendous pressure to "do something," even when misguided action may be worse than no action at all. Thus, a leader who lacks enough information to justify a given dramatic policy initiative might nonetheless propose it, lest voters perceive the leader as insufficiently competent to handle the crisis.

Critics have claimed that the latter tendency is evident in the response to perceived national security crises, such as the September 11, 2001 terrorist attacks. As Swire $(2004,1349)$ argues, "When a crisis hits, ... there are strong pressures to 'do something' to respond to the threat. At that instant, ... [1] egislation that would not otherwise be enacted [due to its adverse impact on civil liberties] thereby becomes law." Other critics have likewise asserted that the desire of elected leaders to appear competent in the face of economic hardship often leads to ill-advised regulatory interventions. Pierce $(1991,9)$ offers the price controls adopted in response to the oil crisis of the 1970s as an example of the general phenomenon that "when Congress responds to intense pressure to 'do something' to solve a problem that is widely believed to be critical, the 'something' it does is often counterproductive." Similar arguments have been leveled against the government response to recent corporate accounting scandals (Ramirez 2007; Romano 2005).

To be clear, we take no position in this article on the appropriateness of any of these particular policies. Although bold government action in response to a perceived crisis is sometimes ill-advised and counterproductive posturing, such actions are sometimes justified by the nature of the emergency. The problem is that it is difficult to tell. For that reason, a rational institutional designer might want to supplement elections with some other mechanism to constrain (or correct for) the perverse incentives that electoral pressures

\footnotetext{
${ }^{1}$ This "posturing" is a variant on what Levy (2004) describes more generally as "anti-herding." We use the shorthand "posturing" to describe this behavior, although we recognize that the term is often used in a different sense.
}

can sometimes create. One such mechanism is judicial review by independent courts. Cole $(2008,1341)$ advances this argument, in the national security context, as follows: "[D]emocracies and political officials will often be tempted to take actions that appear to offer short-term benefits even if they are contrary to our collective long-term interests. Politicians by institutional design think in the short term.... Inscribing commitments in a constitution, enforceable by judges who need not worry about reelection, is an institutional way to encourage consideration of long-term as well as short-term effects." Other scholars have made similar claims (Eisgruber 2001). On this view, even though judicial review is "undemocratic" when considered in isolation, judicial review might enhance rather than undermine the degree to which policy choices reflect the interests of a majority of voters. ${ }^{2}$

Yet, even if one concedes that elections sometimes create the perverse incentives suggested previously, judicial review may not make things better, and may make things worse (Elhauge 1991; Vermeule 2006; Waldron 2006). Indeed, the existence of a "democratic failure" (agency slack between voters and their representatives) does not necessarily justify judicial review any more than the existence of a market failure necessarily justifies government regulation. Critics have highlighted three reasons why judicial review may not be an appropriate response to the policy distortions allegedly created by electoral pressures. The first is $j u$ dicial bias: Judges may have the "wrong" preferences and use their review power in ways that harm voter interests. The second problem is judicial incompetence: Even well-motivated judges may lack the capacity to evaluate the moral and empirical questions at stake in any hard case, such that whatever benefits flow from correct judicial decisions may be outweighed by the costs of erroneous decisions. Third, following a concern raised by Thayer (1893), some critics warn of a kind of judicial overhang (Tushnet 1999) or "moral hazard" (Rogers 2009; Vermeule 2006): Judicial review may cause elected politicians to pay less attention to certain constitutionally protected values because the legislators overrely on the courts to address such concerns.

So, we confront a difficult question: When will judicial review serve voters' interests by ameliorating the distorting effects of short-term electoral incentives on political behavior, and when will judicial review do more harm than good? We develop a political economy framework for addressing this question. ${ }^{3}$ The complexity of the topic means that our contribution is

\footnotetext{
${ }^{2}$ Of course, this is not the only possible justification for "undemocratic" judicial review. Many have argued, for example, that judicial review protects basic moral principles and the rights of vulnerable minorities (or diffuse majorities) against the depredations of the majority or influential interest groups (Dworkin 1985; Ely 1980; Sunstein 1984, 1985). Judicial review might also prevent antidemocratic "lockups" of the political process by incumbents (Ely 1980; Issacharoff and Pildes 1998). We acknowledge these possibilities, but put them to one side in order to focus on the particular argument for judicial review developed in the text.

${ }^{3}$ Despite the vast legal literature on judicial review, relatively little political economy work engages this problem directly. Most democratic accountability models focus on the relationship between voters
} 
necessarily limited. Instead of considering the myriad possible problems that judicial review might plausibly redress, we focus on the incentive that elections create for an incumbent politician to posture by taking bold policy gambles in order to appear competent. Also, although we explicitly incorporate the concern about judicial incompetence, and endogenously derive results related to judicial overhang, we do not incorporate the judicial bias concern. Although these limitations mean that our analysis omits several important issues in debates over judicial review, limiting our analysis in this way allows us to focus on other important issues without the loss of clarity inherent in a "model of everything."

\section{POLITICAL POSTURING WITHOUT JUDICIAL REVIEW}

\section{Baseline Model}

In the baseline model, there is a single Voter and a single elected Leader. The Leader must select one of two policies, $a \in\{n, x\}$, where $a=n$ denotes a "normal" policy and $a=x$ denotes an "extraordinary" policy. One can conceive of the "normal" policy as the status quo; a Leader who selects $a=n$ has decided to "stay the course." The "extraordinary" policy can be thought of as some extreme policy choice (e.g., an intrusive government surveillance program, price controls, seizure of private property) that is usually unwise (from the Voter's and the Leader's perspective), but that might be justified under unusual circumstances. Formally, the policy the Voter would prefer depends on the state of the world, $\omega \in\{n, x\}$, where $\omega=n$ denotes a "normal" state and $\omega=x$ denotes an "extraordinary" state. For simplicity, we assume the Voter receives a policy payoff of 1 if the policy matches the state $(a=\omega)$, and a payoff of 0 otherwise. The prior probability of the normal state is $p>\frac{1}{2}$, so the Voter prefers the normal policy ex ante. The Leader's information about the state depends on his type, $t \in\{l, h\}$, which we will refer to as his "ability." If the Leader is low ability (or "incompetent") $(t=l)$, then his information is no better than the Voter's; such a Leader knows only the prior probability of the normal state $(p)$. The high-ability (or "competent") Leader $(t=h)$, in contrast, learns the true state with certainty. The Leader knows his own ability, but the Voter knows only the prior probability $q \in(0,1)$ that the Leader is competent.

and elected agents (e.g., Austen-Smith and Banks 1989; Persson, Roland, and Tabellini 1997), whereas most models of judicial review employ a separation-of-powers framework that suppresses the accountability relationship with voters (e.g., Ferejohn and Shipan 1990; Tsebelis 2002). Some important work compares decision making by an elected official to decision making by an unelected judge (Komesar 1994; Maskin and Tirole 2004), but the question of whether a judge or a politician should make a decision is distinct from the question of whether a judge should review a politician's decision. Some prior political economy work does investigate how judicial review might affect outcomes in a political agency framework (e.g., Posner 2008; Rogers 1999, 2009; Rogers and Vanberg 2007); our work builds on this strand in the literature.
After the Leader selects the policy $a$, the Voter updates her assessment of the probability the Leader is competent. Denote the Voter's posterior estimate of this probability as $\hat{q}(a)$. This posterior belief can be thought of as the Leader's reputation, with higher or lower values of $\hat{q}$ indicating "better" or "worse" reputations, respectively. There is then an election. ${ }^{4}$ We assume that, all else equal, the Voter's expected utility in future periods (which we do not model explicitly) is an increasing function of the competence of the winning candidate, so the Voter is more likely to reelect an incumbent with a good reputation. Thus, the probability that the Leader wins the election is given by the function $F(\hat{q})$, where $F$ is continuous and strictly increasing in $\hat{q} .{ }^{5}$ We refer to $F(\hat{q})$ as the Leader's electoral strength. The better the Leader's reputation, the greater his electoral strength.

The Leader shares the Voter's policy preferences; all else equal, the Leader prefers the policy to match the state $(a=\omega)$, receiving a policy payoff of 1 when $a=\omega$, and 0 otherwise. The Leader, however, also receives a private benefit from holding office (e.g., ego rents or perks). This private benefit, rather than a difference in policy preferences, creates the agency problem between the Voter and Leader in our model. ${ }^{6}$ Because the Leader cares about both policy and reelection, we write his total utility as $\alpha u+(1-\alpha)$ if he wins reelection, and as $\alpha u$ otherwise, where $u \in\{0,1\}$ is the Leader's policy payoff, $\alpha \in[0,1)$ is the weight the Leader attaches to policy, and $(1-\alpha)$ is the weight he attaches to reelection. ${ }^{7}$ Thus, $\alpha$ is an inverse measure of the Leader's electoral ambition.

To summarize, the baseline model is as follows:

1. Nature determines the state of the world $\omega$ and the Leader's underlying ability $t$.

2. Policy-making phase. The Leader, knowing his ability, implements a policy $a \in\{n, x\}$.

3. Election phase. The Voter, knowing the Leader's policy choice, draws an inference about the Leader's ability. An election is then held, in which the Leader's probability of reelection is an increasing function of the probability the Voter assigns to the Leader being of high ability.

\footnotetext{
${ }^{4}$ We assume that the Voter does not acquire any additional information about the Leader's competence prior to the election. The Voter does not, for example, observe whether the chosen policy was successful.

${ }^{5}$ One natural interpretation is that the challenger's perceived probability of being high ability, realized after the incumbent's choice of $a$, is a random variable with cumulative distribution function $F$.

${ }^{6}$ We assume that the Leader's interest in retaining office is independent of his ability. This assumption, however, may be in tension with our assumption that the Leader shares the Voter's policy preferences: one could argue that a low-ability Leader ought to have a weaker interest in reelection than a high-ability Leader. Although we acknowledge this possibility, we believe that it is substantively reasonable to suppose that a politician's desire for reelection is independent of his underlying ability.

${ }^{7}$ The value of $\alpha$ might be determined, for instance, by whether the election is imminent or far off, whether the Leader is eligible to run for reelection at all (or whether he is constrained by a term limit), the importance of the particular policy at issue relative to other matters, the value of holding office, and so forth.
} 
Before proceeding to the equilibrium analysis, notice that because the low-ability Leader knows only the prior $p>\frac{1}{2}$ that $\omega=n$, the low-ability Leader maximizes the Voter's policy payoff by selecting $a=n$. (Even in a crisis, voters would prefer an incompetent leader to "stay the course" rather than taking action that is likely to prove counterproductive.) In contrast, because the high-ability Leader knows the state, he maximizes the Voter's payoff by matching policy to the state.

\section{Equilibrium}

Our solution concept is Perfect Bayesian Equilibrium. We assume the high-ability Leader always proposes the policy that matches the state. ${ }^{8}$ Hence, to solve for an equilibrium, we solve for the low-ability Leader's equilibrium strategy and the Voter's equilibrium beliefs, where the low-ability Leader's strategy is a probability, $\pi$, of selecting the extraordinary policy. A strategybelief pair is an equilibrium if (1) the low-ability Leader's policy choice (as prescribed by his strategy) maximizes his expected payoff given the Voter's beliefs, and (2) for each policy choice $a$, the Voter's posterior belief that the Leader is high-ability, $\hat{q}(a)$, is derived via Bayes' Rule when possible.

Recall that the Voter would like the low-ability Leader always to propose the normal action, so the Voter is best off policywise when the low-ability Leader's strategy assigns zero probability to the extraordinary action $(\pi=0)$. Our main result in this section establishes, however, that if the Leader cares sufficiently about reelection, there does not exist an equilibrium in which $\pi=0$. To see why, suppose the highability Leader matches policy to the state and the lowability Leader always selects the normal action. Then, when the Voter observed the extraordinary action, she would infer that the Leader's ability is high $(\hat{q}(x)=1)$; in contrast, when the Voter observed the normal action, she would place positive weight on the Leader's ability being low $\left(\hat{q}(n)=\frac{p q}{p q+(1-q)}\right)$. So, given the conjectured strategies, the Leader maximizes his reputation for being high ability - and so maximizes his probability of reelection-by selecting the extraordinary action. However, this means that if the low-ability Leader cares sufficiently about reelection (i.e., $\alpha$ is small), it is not optimal for him always to select the normal action. Thus, if Leaders have sufficient electoral ambition, in any equilibrium in which the high-ability Leader matches policy to the state, the low-ability Leader's equilibrium strategy must assign positive probability to selecting the extraordinary action $(\pi>0)$. This is true despite the fact that selecting the extraordinary action involves the low-ability Leader incurring a net policy cost of $(2 p-1){ }^{9}$ Our first proposition establishes that

\footnotetext{
${ }^{8}$ This simplifies the exposition. We verify in the supplemental online Appendix (http://www.journals.cambridge.org/psr2011007), that matching policy to the state is consistent with equilibrium behavior for the high-ability Leader.

${ }^{9}$ The low-ability Leader's expected policy payoffs from the normal action and extraordinary action are $p$ and $1-p$, respectively. Hence,
}

the low-ability Leader's equilibrium probability of taking uninformed extraordinary action, $\pi_{\text {norev }}^{*}$, is positive when he cares sufficiently about getting reelected, but decreases as he cares more about policy.

\section{Proposition 1. Define}

$$
\bar{\alpha} \equiv \frac{F(1)-F\left(\frac{p q}{p q+(1-q)}\right)}{2 p-1+F(1)-F\left(\frac{p q}{p q+(1-q)}\right)}
$$

In the absence of judicial review, the equilibrium probability with which the low-ability Leader proposes extraordinary action, $\pi_{\text {norev }}^{*}$, is uniquely defined. Furthermore, we have that
a. $\pi_{\text {norev }}^{*}=1-p$ whenever the low-ability Leader cares only about reelection $(\alpha=0)$.
b. $\pi_{\text {norev }}^{*}$ is strictly decreasing in $\alpha$ on the interval $[0, \bar{\alpha})$.
c. $\pi_{\text {norev }}^{*}=0$ whenever $\alpha \geq \bar{\alpha}^{10}$

We can interpret $\pi_{\text {norev }}^{*}$ as a measure of "posturing." In an ideally functioning democracy, a high-ability Leader would match the action to the state, whereas a low-ability Leader would always select the normal action. In the equilibrium described in Proposition 1, the high-ability Leader behaves as he should, but the low-ability Leader may not. When $\pi_{\text {norev }}^{*}>0$, the lowability Leader's electoral interests lead him sometimes to select the extraordinary action despite the absence of sufficient evidence that doing so is in the public interest-indeed, despite the fact that the Leader himself expects a lower policy payoff from the extraordinary action than from the normal action. ${ }^{11}$ Thus, $\pi_{\text {norev }}^{*}$

the net expected policy payoff to the low-ability Leader from the extraordinary action is $1-2 p$.

${ }^{10}$ It is straightforward to show that the effect of $q$ on $\pi_{\text {norev }}^{*}$ is ambiguous.

11 This result is a variant on Levy's (2004) analysis of "anti-herding" (see also Avery and Chevalier 1999; Prendergast and Stole 1996). As noted previously, a closely related family of models generates "pandering" behavior in which a less competent leader's reputational interest causes him to select the policy the voters believe ex ante is more likely to be correct (Canes-Wrone, Herron, and Shotts 2001; Prat 2005; Prendergast 1993). The principal difference between these two classes of models concerns the quality of the less competent leader's information. In pandering models, even a less competent leader gets a sufficiently reliable signal that, but for electoral incentives, he would prefer to follow his signal. Furthermore, in these models, the conditional probability that the low-ability leader gets the wrong signal is equal (or nearly equal) for all states. These assumptions mean that in the absence of electoral incentives less competent leaders disproportionately prefer the policy that is ex ante less likely to be correct. In contrast, in posturing models, the less competent leader's signal is insufficiently strong to alter his prior belief about the state; thus, absent electoral incentives, less competent leaders disproportionately prefer the policy favored by their prior. As should be clear from the comparison, the basic dynamic underlying both types of models is essentially the same: When less competent leaders disproportionately prefer one policy, they have an electoral incentive to choose the other policy, lest voters infer from the leader's choice that he is incompetent. We therefore expect that our analysis of the impact of judicial review would be similar in a pandering model, although we defer full consideration to future research. 
measures the degree to which the Leader's interest in reelection distorts his equilibrium behavior away from what one would observe in an ideally functioning representative democracy. ${ }^{12}$

Such posturing behavior hurts the Voter in two ways. First, and most obviously, absent additional information, the extraordinary action has a negative expected policy payoff. Second, the distortion in the low-ability Leader's behavior can make the electoral mechanism a less efficient means for the Voter to select competent Leaders because the incumbent Leader's action provides less information to the Voter about the Leader's ability. ${ }^{13}$ One solution to the former problem might be to eliminate the electoral constraint (say, by imposing a term limit) or to keep the policy decision secret until after the election (Fox 2007; Prat 2005). Such approaches, however, would further undermine the capacity of the electoral system to improve the average competence of Leaders over time and could have other adverse consequences as well. For these reasons, institutional designers might contemplate other mechanisms that preserve the system of selecting the Leader via competitive elections, but reduce or compensate for the distortion induced by the low-ability Leader's electoral incentives. Judicial review may be one such mechanism.

\section{POLITICAL POSTURING WITH JUDICIAL REVIEW}

\section{Modified Game}

Now that we have isolated a particular form of electorally induced distortion, we can analyze the impact of judicial review by modifying the baseline model as follows: After the Leader selects action $a$, but prior to the election, the Leader's proposed action is reviewed by a Judge. ${ }^{14}$ The Judge issues a decision $d \in\{$ uphold, strike\}; if the Judge upholds the Leader's proposal $(d=$ uphold $)$, the Leader's proposed action is implemented, but if the Judge strikes down the Leader's proposal $(d=$ strike), the Judge imposes the alternative policy as the final outcome (i.e., if $a=x$ and $d=$ strike, then the final policy is $n$ ). Our analysis incorporates, in stylized fashion, three characteristics of judicial review that are often cited as important distinctions between judicial review and other forms of oversight or institutional control.

First, the Judge in our model has the power to strike down the Leader's action, but cannot implement a

\footnotetext{
12 Notice that the probability that the final policy does not match the state is equal to $(1-q)\left[p \pi_{\text {norev }}^{*}+(1-p)\left(1-\pi_{\text {norev }}^{*}\right)\right]$, and because $p>\frac{1}{2}$, this probability is strictly increasing in $\pi_{\text {norev }}^{*}$.

13 To illustrate with an extreme case, if $\pi_{\text {norev }}^{*}=1-p$, then lowability and high-ability Leaders select $a=x$ with equal probabilities, and the Voter learns nothing about the Leader's type from his policy choice.

14 Because there is usually some litigant willing to challenge significant and controversial policy decisions, we make the simplifying assumption that judicial review is automatic. We later consider, informally, how one might endogenize the review process, such that review only arises if a litigant makes the strategic decision to challenge government action. The subsequent analysis also notes how the results might change if review occurs only after the election.
}

more refined incentive scheme that offers variable payments or penalties to the Leader that depend on the Leader's proposal. This is consistent with conventional understandings of the nature and limits of judicial power, and captures one of the ways that judicial review of government action is believed to differ from, for example, legislative oversight of a bureaucratic agency, or a firm's supervision of its employees. ${ }^{15}$

Second, we assume that the Judge is insulated both from popular elections and direct interference by the Leader, and that the Judge does not consider how her decisions will affect the election. ${ }^{16}$

Third, we incorporate the concern about (relative) judicial incompetence by assuming that although the Judge's analysis of a proposed government action conveys some decision-relevant information (i.e., information about the true state), the Judge's information is never by itself strong enough to overcome the Judge's prior beliefs. We model this by assuming that after the Leader proposes action $a$, the Judge gets a private signal $s \in\{n, x\}$ of the state of the world. The probability that the Judge's signal is accurate (i.e., $s=\omega$ ), which is independent of the state, is $\gamma \in\left[\frac{1}{2}, p\right)$. The signal $s$ can be interpreted as a reduced-form expression of the Judge's assessment of the evidence proffered by attorneys during litigation proceedings. ${ }^{17}$ The $\gamma$ parameter, which is common knowledge, can be interpreted as the Judge's "ability." 18 The assumption that $\gamma<p$

\footnotetext{
15 A strain in legal scholarship has challenged this assumption, arguing that judicial review can sometimes raise the costs of enacting certain government policies without necessarily prohibiting them (Stephenson 2008; Young 2000). As we show in the working paper version of this article (Fox and Stephenson 2009), if the Judge in our model were able to raise the cost of enacting $a=x$, then judicial review could eliminate the posturing problem. That said, there are a number of potential obstacles-including the problems of credible commitment and accurate calibration-that may limit the applicability of such a strategy. It is thus reasonable to analyze settings where the Judge must make a simple yes-or-no decision as to whether to uphold the Leader's proposal.

${ }^{16}$ Although there is evidence that judges are sensitive to public opinion and are mindful of the political and electoral repercussions of their decisions (Friedman 2009; Schauer 2000), these considerations probably matter much less to life-tenured, politically insulated judges than they do to elected politicians. We capture this relative difference, in stylized form, by stipulating that the Judge cares only about getting the correct answer in the case before her.

${ }^{17} \mathrm{We}$ assume that although court proceedings may be public, the signal $s$ (the Judge's assessment of the evidence, as distinct from the evidence itself) is the Judge's private information. Although the Judge in principle could choose to reveal her signal-for instance, by including it in her written opinion-we believe that it is reasonable to presume $s$ remains private information. First, actual case dispositions are likely to be more salient for most voters than the details of a given case opinion. Also, a Judge who defers to the Leader's proposal might not have an incentive to disclose her contrary signal because doing so may be mildly costly and does not affect the case outcome. Furthermore, if the Judge must pay some small cost to acquire the signal, then she may not bother to do so if she does not expect her ultimate decision to be influenced by the realization of $s$. The working paper version of this article considers how the results change if the Judge can publicly disclose $s$ (Fox and Stephenson 2009).

${ }^{18}$ We treat $\gamma$ as exogenous. Of course, the likelihood that the Judge draws the correct inference about the true state will depend on among other things, the quality of the lawyering on the case and the Judge's own decision to invest effort in analyzing the issues (Stephenson 2011; Tullock 1979). For present purposes, it suffices
} 
guarantees that the Judge's signal is never sufficient, on its own, to overcome the prior presumption that the normal action is correct. ${ }^{19}$ Also, the Judge does not know the Leader's true type, but knows only the prior probability, $q$, that the Leader is competent.

We further assume that the Judge cares only about policy, and like the Voter, receives a payoff of 1 if the policy matches the state, and a payoff of 0 otherwise. This assumption is potentially vulnerable to two criticisms. First, our model does not explicitly incorporate specifically legal constraints on how a judge evaluates a government decision; judges may often care about legal rules that have little to do with policy consequences. Yet many of the most salient forms of constitutional (and nonconstitutional) judicial review, both in the United States and elsewhere, call on judges to decide whether a particular government action is "reasonable," "supported by a compelling interest," "proportional," and the like; judicial review under these relatively openended balancing inquiries is broadly consonant with how we model it here. The second and more serious difficulty with our assumption that the Judge prefers to match policy to the state is that our model does not incorporate the judicial bias problem that is central in many debates about judicial review. We acknowledge this as an important limitation of our analysis. That said, we also assume that the Leader shares the Voter's policy preferences. These assumptions, taken together, mean that our model investigates costs and benefits of judicial review that arise from sources other than preference divergence. ${ }^{20}$

To summarize, the modified game is as follows:

1. Nature determines the state of the world $\omega$ and the Leader's underlying ability $t$.

2. Policy-making phase. The Leader, knowing his ability, proposes a policy $a \in\{n, x\}$.

3. Judicial review phase. The Judge, knowing the Leader's policy proposal $a$ and her own signal $s$, issues a decision $d$, either upholding or striking down the Leader's proposal. If the Judge upholds the proposal, then it is implemented; otherwise, the alternative policy is implemented.

4. Election phase. The Voter, knowing the Leader's policy choice and the Judge's decision, draws an inference about the Leader's ability. An election is then held in which the Leader's probability of reelection is an increasing function of the probability the Voter assigns to the Leader being of high ability.

to treat $\gamma$ as the equilibrium accuracy of the Judge's signal when these other decisions have been made rationally.

${ }^{19}$ Formally, $\gamma<p$ implies that $\operatorname{Pr}(\omega=n \mid s=x)>\frac{1}{2}$. This means that a Judge whose only information beyond her prior $(p)$ about the state is a signal of $s=x$ still believes that $\omega=n$ is the the more likely state.

${ }^{20}$ We do not believe that this unduly stacks the deck for or against judicial review: The assumption that the Judge prefers to match policy to the state rules out one common argument against judicial review, but the assumption that the Leader also prefers (on policy grounds) to match policy to the state rules out one common justification for review.
Before proceeding to the equilibrium analysis, we note that even in the Judge's presence, the Voter's policy payoff is maximized when the high-ability Leader matches policy to the state and the lowability Leader selects the normal policy. That the lowability Leader should never select the extraordinary action follows from our assumptions that the low-ability Leader knows only the prior that $\omega=n$ when proposing policy and that the Judge's signal of the state is not strong enough on its own to support implementing the extraordinary action (i.e., $\gamma<p$ ). ${ }^{21,22}$

\section{Equilibrium}

As before, we assume the high-ability Leader always proposes the policy that matches the state $(a=\omega)$. We also assume that there is no judicial review if the Leader proposes the normal action (i.e., if the Leader proposes no change from the status quo). That is, only extraordinary proposals are "justiciable." 23 To solve for an equilibrium under these assumptions, we must solve for the probability that the low-ability Leader proposes the extraordinary action, and for the behavior of the Judge on observing such a proposal. As before, we denote the low-ability Leader's strategy by the probability $\pi$ that he chooses the extraordinary action. We write the Judge's strategy as $\left(\sigma_{n}, \sigma_{x}\right)$, where $\sigma_{n}$ is the probability that the Judge upholds the extraordinary action even though her signal favors the normal action $(s=n)$, whereas $\sigma_{x}$ is the probability that the Judge upholds the extraordinary action when her signal favors the extraordinary action $(s=x)$.

We must also specify beliefs. As in the baseline model, denote the Voter's posterior about the Leader's ability when the normal action is proposed as $\hat{q}(n)$. However, in contrast to the baseline model, denote the Voter's posterior about the Leader's ability when the extraordinary action is proposed as $\hat{q}(x, d)$, where $d$ denotes the Judge's decision to either uphold or strike

\footnotetext{
21 In contrast, if $\gamma>p$, then the low-ability Leader has a policy incentive to pass her decision off to the Judge, instructing the Judge to determine policy based upon her signal. Moreover, in the event that only the extraordinary action is justiciable, assuming $\gamma>p$ would lead to a situation in which the low-ability Leader might take uninformed extraordinary action simply to bring the expertise of the Judge to bear on the question. We do not consider this case in the main text, but we show in the online Appendix that our welfare results concerning the negative consequences of review-namely, that the voter can be worse off policywise with review than without-can hold even when $\gamma>p$

22 Although we focus principally on judicial review in what follows, we note that our analysis may have broader application to any oversight scheme in which one agent, subject to electoral pressures or other career concerns, makes a decision that can be reviewed by a second agent who lacks such career concerns, but who may not have as good information. For example, our analysis might apply to review of local democratic decisions by a national or supranational agent that may lack local knowledge, but that has less incentive to seek popularity with the local electorate.

23 This assumption, which is often empirically plausible, simplifies the exposition. We show in the online Appendix that this assumption is benign because, even if $a=n$ were justiciable, the Judge would always uphold the normal policy provided that the high-ability Leader follows his signal.
} 
the extraordinary action. Thus, with review, the Voter takes account not only of the Leader's proposal, but also the Judge's decision, when forming beliefs about the Leader's type. In addition to specifying beliefs for the Voter, we must also specify beliefs for the Judge. In particular, in deciding whether to uphold the extraordinary action, the Judge must update her prior that the state is normal based upon her signal $(s)$ and the fact that the extraordinary action has been proposed. Denote this posterior $\hat{p}(s)$.

The strategies of the low-ability Leader and the Judge, together with the beliefs of the Judge and the Voter, constitute an equilibrium if (1) the low-ability Leader's policy choice (as prescribed by his strategy) maximizes his expected payoff given the Judge's strategy and the Voter's posterior beliefs about the Leader's competence; (2) for each private signal $s \in\{n, x\}$, the Judge's ruling (as prescribed by her strategy) maximizes her expected payoff given her posterior belief about the state; and (3) beliefs (of the voter and the Judge) are derived via Bayes' Rule whenever possible. $^{24}$

Our equilibrium analysis proceeds in three stages. First, we characterize the equilibrium behavior of the Leader, taking the Judge's strategy as exogenous. This partial-equilibrium analysis allows us to assess the effect of aggressive judicial review on the level of posturing. Second, we characterize the equilibrium behavior of the Judge, taking the Leader's strategy as exogenous. This partial-equilibrium analysis clarifies how the level of posturing affects the aggressiveness with which the Judge reviews the Leader's proposals. Third, we combine these partial-equilibrium analyses to characterize the equilibria of the judicial review game.

Effect of the Judge's Review Strategy on the Level of Posturing. Although our model does not permit a comprehensive assessment of the effects of judicial review, it does allow us to investigate how judicial review affects the particular form of distortion we isolated in the previous section: the propensity of low-ability leaders to "posture" by proposing bold (and probably unjustified) action in order to appear competent. We now consider that question, taking the Judge's strategy as exogenous.

Most extant discussions of the effect of judicial review on policy outcomes presume that the reviewing court makes some independent decision, based on the court's own analysis, about whether to uphold the proposed government action. In our model, this would imply a situation in which the Judge follows her signal, upholding the extraordinary policy if $s=x$, but striking it down if $s=n$ (i.e., $\sigma_{n}=0, \sigma_{x}=1$ ). We label this form of judicial review as active review. There are two other

\footnotetext{
${ }^{24}$ Because the high-ability Leader always matches policy to the state, $x$ is always chosen with positive probability, so $\hat{p}$ can be completely specified via Bayes' Rule. In contrast, it is not always possible to completely specify $\hat{q}$ via Bayes' Rule. For example, if the Judge's strategy calls for her always to uphold the Leader's proposal of $a=$ $x$, then $\hat{q}(x$, strike $)$ cannot be derived via Bayes' Rule. That said, the low-ability Leader's incentives are fully determined by on-path beliefs, so the specification of off-path beliefs is inconsequential.
}

pure strategies the Judge might employ, however. First, the Judge might adopt a passive approach, upholding the Leader's proposal regardless of the Judge's own signal (i.e., $\sigma_{n}=\sigma_{x}=1$ ). Second, the Judge might employ a strict review strategy, striking down the extraordinary action in all cases (i.e., $\left.\sigma_{n}=\sigma_{x}=0\right) .{ }^{25} \mathrm{We}$ refer to any equilibrium in which the Judge employs an active review strategy as an active equilibrium. We define passive equilibrium and strict equilibrium analogously. The low-ability Leader's equilibrium strategy, conditional on the Judge adopting the active strategy, is denoted $\pi_{\text {act }}^{*}$, whereas $\pi_{\text {pass }}^{*}$ and $\pi_{\text {strict }}^{*}$ denote the Leader's equilibrium strategy given passive and strict review, respectively.

We can now address the question of whether judicial review increases or decreases posturing, taking the Judge's review strategy as exogenous:

\section{Proposition 2.}

a. Passive review. In a passive equilibrium, posturing is the same as in the baseline model without judicial review (i.e., $\pi_{\text {pass }}^{*}=\pi_{\text {norev }}^{*}$ ).

b. Strict review. In a strict equilibrium, posturing is weakly greater than that in the no review case (i.e., $\pi_{\text {strict }}^{*}=1-p \geq \pi_{\text {norev }}^{*}$ ).

c. Active review. In an active equilibrium, the level of posturing, $\pi_{a c t}^{*}$, is uniquely defined, and can be greater than or less than that in the no review case (i.e., the ordering of $\pi_{\text {act }}^{*}$ and $\pi_{\text {norev }}^{*}$ is ambiguous). ${ }^{26}$

Part (a) of Proposition 2 is unsurprising: If the Judge is passive, the model with judicial review is functionally equivalent to the baseline model with no review. Part (b) is also straightforward: If the Judge uses a strict review strategy, the final outcome is always the normal policy; because that outcome is a foregone conclusion, the low-ability Leader's policy choice is driven solely by electoral considerations. Thus, in a strict equilibrium, the low-ability Leader selects $a=x$ with the same probability as the high-ability Leader $(1-p)$. Part (c) of Proposition 2, concerning the effect of active judicial review, is more complicated and more relevant to debates over the impact of judicial review on democratic performance. The reason that active review may increase or decrease posturing is that active review affects the low-ability Leader's incentives through two quite different channels, and these two effects may cut in opposite directions. One of these effects concerns the impact of active review on the likely policy consequences if the low-ability Leader proposes the extraordinary action. The other effect concerns the impact of active review on the likely reputational consequences for the low-ability Leader who proposes the extraordinary action. Let us consider each in turn.

\footnotetext{
${ }^{25}$ A fourth pure strategy, in which the Judge always does the opposite of her signal, is implausible and never occurs in an equilibrium in which the high-ability Leader matches policy to the state. We consider the possibility that the Judge might employ a mixed strategy when analyzing the equilibria of the judicial review game.

${ }^{26}$ It is straightforward to show that $\pi_{a c t}^{*}$ is weakly decreasing in $\alpha$, but the effects of $\gamma$ and $q$ on $\pi_{a c t}^{*}$ are ambiguous.
} 
First, the low-ability Leader's incentive to propose extraordinary action depends in part on the expected policy consequences of making such a proposal. Because the extraordinary action is probably a bad idea, a low-ability Leader is more likely to propose such action if there is some probability that the Judge will strike it down. This would be true even if the Judge struck down proposals at random; the fact that the Judge's signal is somewhat informative strengthens the effect. This "bailout effect" means that active judicial review tends to increase posturing all else equal (although it will also correct some erroneous policy choices). This observation is broadly consistent with the "judicial overhang" hypothesis that judicial review will make elected leaders more reckless because they can rely on courts to screen out objectionable policies. It is also consistent with the related claim that elected officials are sometimes pleased-perhaps even relieved-when the courts strike down a policy measure that the enacting officials viewed as ill advised, but felt pressured by electoral interests to propose (Hirschl 2000; Salzberger 1993).

Active review also has a second effect, however: As long as the Judge's signal is somewhat informative, active review communicates useful information to the Voter about the true state, which the Voter can use to update her assessment of the Leader's competence. ${ }^{27}$ Call this the "legitimation effect" of active judicial review. $^{28}$ This effect can dampen the low-ability Leader's electoral incentive to propose the extraordinary action. ${ }^{29}$ This is because, holding the low-ability Leader's strategy fixed, the introduction of a Judge who employs an active review strategy reduces the low-ability Leader's expected reputation from proposing $a=x$. To see why, note that when the Judge overrules the Leader, the Leader's reputation suffers; because the low-ability Leader is more likely to be overruled than the high-ability Leader, the former's expected reputation from proposing $a=x$ is worse than the latter's. This fact (taken together with the Martingale property of Bayesian posteriors ${ }^{30}$ ) implies that the low-ability

\footnotetext{
27 This is similar to how an informative media's reporting about the state of the world can affect public perceptions of the competence of elected officials, as discussed in Ashworth and Shotts (2010). A crucial difference, however, is that the media in their model only communicate a signal about the state, whereas in our model the Judge's decision simultaneously communicates information about the state and affects the policy outcome directly. This difference reflects an important substantive difference between the media and the judiciary as constraints on elected officials.

${ }^{28}$ Although there is little empirical evidence on the question of how judicial validation or invalidation of a policy affects public opinion of the officials who enacted it, there is suggestive evidence that judicial rulings may affect public evaluations of the policies themselves (Clawson, Kegler, and Waltenburg 2001; Hoekstra and Segal 1996).

${ }^{29}$ If we assume that the electoral strength function $F$ is concave, then the legitimation effect will dampen the low-ability Leader's electoral incentive to propose $a=x$. In contrast, when $F$ is sufficiently convex, the addition of the Judge can increase the low-ability Leader's electoral incentive to propose $a=x$. See the working paper version of this article (Fox and Stephenson 2009) for further discussion of this subtlety.

${ }^{30}$ The Martingale property of Bayesian posteriors implies that the Voter's posterior about the Leader's ability on observing $x$ pro-
}

Leader's expected reputation from proposing $a=x$ is lower in the presence of active judicial review than in the case without judicial review.

Thus, active review affects the low-ability Leader's incentive to propose $a=x$ via two channels that often work at cross purposes. On the one hand, the bailout effect reduces the policy costs to the low-ability Leader from proposing the extraordinary action. This makes selecting $a=x$ more attractive to the low-ability Leader. On the other hand, the legitimation effect can reduce the low-ability Leader's electoral benefit from proposing $a=x$. Thus, depending on the relative magnitudes of the bailout and legitimation effects, active review can increase or decrease posturing, relative to the no review baseline. ${ }^{31}$

We conclude this subsection by noting that our discussion so far has considered only the impact of judicial review on the level of posturing, not its potential to correct for this sort of distortion (as when the Judge strikes down a low-ability Leader's incorrect decision) or its potential to obstruct desirable government initiatives (as when the Judge incorrectly strikes down an extraordinary proposal). ${ }^{32}$ We take up these factors in the next section.

\section{Effect of Posturing on the Judge's Review Strategy.} The preceding subsection characterized the behavior of the Leader, taking the Judge's review strategy as fixed. However, the Judge in our model is also a strategic actor. We now investigate the conditions that give rise to different forms of judicial behavior, temporarily treating the level of posturing, $\pi$, as exogenous.

Begin by considering the Judge's incentives to uphold the extraordinary action when it is proposed. Because the Judge cares only about policy, her decision whether to uphold the extraordinary action will turn on her posterior belief about which state-normal or extraordinary-is more likely. The Judge initially knows only the prior $p$ that the state is normal. However, at the time the Judge must decide whether to uphold the extraordinary action, she has two additional pieces of information at her disposal. The first is her signal, $s$. Naturally, the Judge assigns more weight to the state being extraordinary when her signal so indicates $(s=x)$ than when her signal points to the state being normal $(s=n)$. The second piece of information the Judge has when she must decide whether to

posed, $\hat{q}(x)$, must equal the Voter's expected posterior on observing $x$ proposed and the Judge's decision $d, \hat{q}(x) E_{d}[\hat{q}(x, d) \mid t=$ $h]+(1-\hat{q}(x)) E_{d}[\hat{q}(x, d) \mid t=l]$.

${ }^{31}$ If our model were modified such that review occurred after the election, such review would continue to create some form of bailout effect, but no legitimation effect. Hence, in such a model, review would exacerbate posturing relative to the no review baseline. We note, however, that in the real world, there still might be some form of legitimation effect from such delayed review if the Leader has an interest in his reputation beyond its immediate impact on the next election.

32 Formally, under active review, the probability that the Leader incorrectly proposes extraordinary action in the normal state is $p(1-q) \pi_{a c t}^{*}$; the probability that the extraordinary policy is incorrectly implemented is $(1-\gamma) p(1-q) \pi_{a c t}^{*}$; and the probability that the active Judge incorrectly strikes down the extraordinary policy in the extraordinary state is $(1-\gamma)(1-p)\left(q+(1-q) \pi_{a c t}^{*}\right)$. 


\section{FIGURE 1. Judge's Posterior That the State Is Normal as a Function of her Signal and the Level of Posturing}

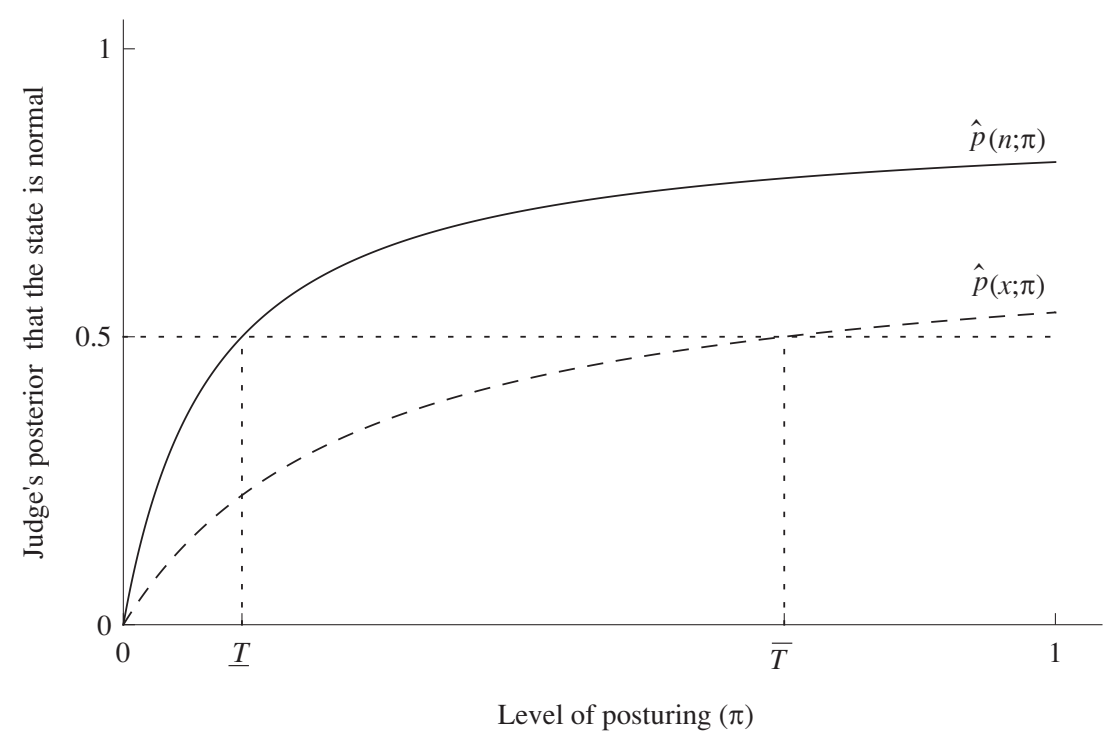

Notes: Suppose that the high-ability Leader matches policy to the state, the low-ability Leader selects the extraordinary action with probability $\pi$, and the Judge observes the extraordinary action proposed. Given that the Judge's signal of the state $s=n, \hat{p}(n ; \cdot)$ is the graph of the Judge's posterior belief that the state is normal as a function of the level of posturing $\pi . \hat{p}(x ; \cdot)$ is analogously defined for the case in which $s=x$. Given that $s=n, T$ gives the maximal level of posturing $\pi$ such that the Judge believes that the extraordinary state is at least as likely as the normal state. $\bar{T}$ is analogously defined for the case in which $s=x$. Notice that it is only when $\pi \in(\underline{T}, \bar{T})$ that the Judge's posterior about which state is more likely hinges on the signal of the state that she receives. For this figure, we set $p=0.8, \gamma=0.65$, and $q=0.45$.

uphold the extraordinary action is the fact that the Leader proposed such action. The Judge knows that the high-ability Leader proposes extraordinary action if, but only if, the state is extraordinary. However, the Judge also knows that the low-ability Leader, who has no private information regarding the state, proposes extraordinary action with probability $\pi$. It follows that the strength of the inference the Judge can draw from the Leader's proposal of the extraordinary action is inversely proportional to $\pi$. For sufficiently low values of $\pi$, the Judge can be quite certain that the state is extraordinary if the Leader proposed extraordinary action; however, this becomes less true as $\pi$ increases. Thus, increasing the rate of posturing $\pi$ can only increase the Judge's incentive to strike the extraordinary action when it is proposed.

Figure 1 plots the Judge's posterior belief that the state is normal as function of both her signal $s$ and the low-ability Leader's strategy $\pi$. To highlight the dependency of this posterior on the rate of posturing $\pi$, we write it as $\hat{p}(s ; \pi) .{ }^{33}$ Figure 1 indicates two key thresholds, $\underline{T}$ and $\bar{T}$. When $\pi<\underline{T}$ and $a=x$, the Judge believes the extraordinary state is more likely than the

\footnotetext{
${ }^{33}$ To be precise, $\hat{p}(s ; \pi)$ is the Judge's posterior belief (derived via Bayes' Rule) that $\omega=n$ when $a=x$ and her signal is $s$, given that the high-ability Leader matches policy to the state and the low-ability Leader selects $a=x$ with probability $\pi$. The online Appendix establishes that $\hat{p}(x ; \pi)=\frac{(1-\gamma)(1-q) \pi p}{(1-\gamma)(1-q) \pi p+\gamma(q+(1-q) \pi)(1-p)}$ and that $\hat{p}(n ; \pi)=\frac{\gamma(1-q) \pi p}{\gamma(1-q) \pi p+(1-\gamma)(q+(1-q) \pi)(1-p)}$.
}

normal state, even if the Judge's own signal is $s=n$; thus, the Judge has a strict incentive to uphold. In contrast, when $\pi>\bar{T}$ and $a=x$, the Judge believes the normal state is more likely than the extraordinary state, even if the Judge's own signal is $s=x$; this gives the Judge a strict incentive to strike down the Leader's extraordinary proposal. It is only when $\pi \in(\underline{T}, \bar{T})$ that the Judge's posterior about whether the Leader's extraordinary proposal is justified depends upon her signal. For this intermediate range of posturing, the information contained in the prior (which favors the normal state) and the information contained in the Leader's extraordinary proposal (which favors the extraordinary state) offset sufficiently that the Judge's own signal becomes decisive. As the next proposition indicates, the level of posturing $\pi$ in relationship to the thresholds $T$ and $\bar{T}$ determines the Judge's equilibrium behavior-namely, whether she adopts a passive, active, or strict strategy.

Proposition 3. Define the following two threshold values:

$$
\underline{T} \equiv\left(\frac{q(1-p)}{1-q}\right) \frac{(1-\gamma)}{p-(1-\gamma)}
$$

and

$$
\bar{T} \equiv\left(\frac{q(1-p)}{1-q}\right) \frac{\gamma}{p-\gamma} .
$$


In an equilibrium in which the low-ability Leader selects $a=x$ with probability $\pi^{*}$, we have

a. If $\pi^{*}<\underline{T}$, then the Judge adopts the passive strategy, upholding $a=x$ regardless of her signal s.

b. If $\pi^{*} \in(\underline{T}, \bar{T})$, then the Judge adopts the active strategy, upholding $a=x$ if $s=x$, but striking $a=x$ when $s=n$.

c. If $\pi^{*}>\bar{T}$, then the Judge adopts the strict strategy, striking $a=x$ regardless of her signal.

d. If $\pi^{*}=\underline{T}$, then the Judge is indifferent between upholding and striking $a=x$ when $s=n$, but upholds $a=x$ whenever $s=x$.

e. If $\pi^{*}=\bar{T}$, then the Judge strikes $a=x$ when $s=n$, and is indifferent between upholding and striking $a=x$ when $s=x .^{34}$

Although we defer a comprehensive consideration of the welfare effects of judicial review until the next section, one welfare implication of Proposition 3 is sufficiently important (both substantively and for developing intuition) that we state it here.

Remark 1: Rational Judicial Activism The Judge strikes down the extraordinary action only when doing so does not harm her expected policy payoff, which is identical to the Voter's expected policy payoff. Thus, if the level of posturing $(\pi)$ is fixed, then judicial review weakly improves Voter welfare relative to the baseline no review case.

This result is notable in light of a familiar objection to judicial review that emphasizes judicial incompetence. One might believe that for sufficiently low levels of judicial ability $(\gamma)$, introducing judicial review would harm Voter welfare because ignorant Judges would strike down policies adopted by more competent elected Leaders. Our analysis, however, demonstrates that low judicial ability is not a sufficient condition for judicial review to have adverse effects on Voter welfare. The reason is that, in our model, the Judge, like Socrates, is aware of the limits of her knowledge, and she rationally discounts the inferences she draws from her own signal accordingly. Consequently, when the Judge's ability is sufficiently low, she tends to defer to the Leader. Such passive judicial review is irrelevant but not harmful. ${ }^{35}$

\footnotetext{
${ }^{34}$ One implication of this proposition is that an equilibrium in which the Judge uses a mixed strategy can only arise when $\pi^{*}=\underline{T}$ or $\pi^{*}=$ $\bar{T}$. Even when $\pi^{*}=\underline{T}\left(\pi^{*}=\bar{T}\right)$, randomizing between upholding and striking the extraordinary action is consistent with equilibrium behavior for the Judge only when $s=n(s=x)$.

35 Although the "judicial incompetence" criticism usually emphasizes that judges lack information or expertise (i.e., that their signals are inaccurate), some have hypothesized that judges may also exhibit systematically irrational behavior-for example, overconfidence in their own signals. The most prominent such hypothesis maintains that judges are swayed excessively by the individual cases before them (Schauer 2006; Vermeule 2009). We acknowledge the possibility that judicial incompetence may lead to worse outcomes in the presence of this or other forms of judicial irrationality, even if the judge is unbiased. The extant literature, however, does not always sharply distinguish arguments about why judges are less informed
}

Having established that the Judge's optimal review strategy depends on the level of posturing $\pi$ in relationship to $\underline{T}$ and $\bar{T}$, we may be interested in comparative statics on $\underline{T}$ and $\bar{T}$ because changes in these thresholds can affect the Judge's review strategy, even holding the level of posturing fixed. These comparative statics are as follows.

\section{Remark 2: Impact of Leader and Judge Characteristics on Judicial Strategy}

a. The lower threshold $\underline{T}$ is decreasing in judicial ability $(\gamma)$, whereas the upper threshold $\bar{T}$ is increasing in $\gamma$.

b. $\underline{T}$ and $\bar{T}$ are independent of the weight the Leader attaches to policy $(\alpha)$.

c. $\underline{T}$ and $\bar{T}$ are both increasing in the probability of $a$ competent leader $(q)$.

Part (a) implies that as judicial ability $(\gamma)$ increases, the interval $[\underline{T}, \bar{T}]$ expands, meaning the active strategy is optimal for a wider range of posturing levels. This is intuitive: The more accurate the Judge's signal, the greater the Judge's payoff from relying on it. Part (b) follows from the fact that the Judge's incentives are not directly affected by parameters of the Leader's payoff function. To see the intuition for part (c), note that if we hold $\pi$ fixed and increase the probability of a competent Leader, the Judge can draw a stronger inference about the state from the Leader's proposal. This makes the passive strategy more attractive relative to the active strategy (i.e., $\underline{T}$ shifts up) and the active strategy more attractive relative to the strict strategy (i.e., $\bar{T}$ shifts up).

\section{Equilibria of Judicial Review Game}

In this section, we move from our partial-equilibrium analyses, in which either the Leader or the Judge's behavior was taken as exogenous, to a generalequilibrium analysis in which both the Leader and the Judge's behavior is endogenous. Our objective is to characterize the outcome of the strategic interaction between the Leader and the Judge as a function of the model's underlying parameters. The main result of this section illuminates how changes in the competence of the Leader $(q)$ and the Judge $(\gamma)$ affect the low-ability Leader's equilibrium level of posturing and the Judge's equilibrium review strategy. ${ }^{36}$

than other actors from arguments about why judges are systematically less rational than other actors. As for the specific argument that judges attach undue salience to the cases before them, it is not clear how strong the effect actually is relative to potentially countervailing considerations, such as the additional information contained in a particular case or series of cases (Rogers 2001; Sherwin 2006), and the analogous tendency of elected officials to overreact to salient events (Kuran and Sunstein 1999).

${ }^{36}$ Our characterization of the conditions under which passive and active equilibria exist is incomplete, because the closed-form solution for the low-ability Leader's equilibrium strategy in nonstrict equilibria tends to be analytically intractable. This is because the low-ability Leader's net expected payoff from proposing $a=x$ is a nonlinear 
Combining Propositions 2 and 3 yields conditions for the existence of passive, strict, and active equilibria. Namely, passive equilibria exist if and only if $\pi_{\text {pass }}^{*} \leq \underline{T}$, strict equilibria exist if and only if $\bar{T} \leq \pi_{\text {strict }}^{*}$, and active equilibria exist if and only if $\underline{T} \leq \pi_{a c t}^{*} \leq \bar{T}$. Thus, the fact that $\pi_{\text {pass }}^{*}$ is bounded above by $(1-p)^{37}$ means that a sufficient condition for passive equilibria is $1-p \leq \underline{T}$. Furthermore, the fact that $\pi_{\text {strict }}^{*}=1-p$ means that a necessary and sufficient condition for strict equilibria is $\bar{T} \leq 1-p$. Finally, the fact that $\pi_{a c t}^{*}$ is bounded above by 1 means that a necessary condition for active equilibria to exist is that $\underline{T} \leq 1$. These inequalities, together with the definitions of $T$ and $\bar{T}$ in Proposition 3 , allow us to provide a partial characterization of the respective regions of the parameter space under which passive, strict, and active equilibria exist.

\section{Proposition 4.}

a. Passive equilibria exist if $q \geq \frac{p+\gamma-1}{p}$ (i.e., whenever the prior belief that the Leader is high ability is sufficiently large relative to the accuracy of the Judge's signal).

b. Strict equilibria exist if and only if $q \leq \frac{p-\gamma}{p}$ (i.e., whenever the prior belief that the Leader is high ability is sufficiently small).

c. Active equilibria exist only if $q \leq \frac{p+\gamma-1}{p \gamma}$ (i.e., when the prior belief that the Leader is high ability is not too large).

d. Equilibria always exist; parameter values exist in which more than one judicial strategy is consistent with equilibrium behavior; parameter values also exist in which all equilibria involve the Judge employing a mixed strategy.

This proposition tells us that equilibria are passive when the probability of a competent Leader $(q)$ is sufficiently large. It also tells us that strict equilibria exist when the probability of a competent Leader is sufficiently small. The basic intuition is straightforward: If most Leaders are high ability, the selection of the extraordinary proposal is sufficiently informative that it is optimal for the Judge to defer to the Leader. In contrast, when the Leader is likely to be incompetent, the Judge will be considerably more skeptical of a proposed extraordinary action. Hence, if $q$ is low and the level of posturing is high, then the Judge will overrule the Leader regardless of her signal. Part (c) of Proposition 4 leaves open the possibility of active equilibria (but only if $q$ is not too large).

To complement our analytic results, we characterize graphically the conditions under which passive, strict, and active equilibria exist. In Figure 2, we vary the Judge's ability $(\gamma)$ and the probability of a competent Leader $(q)$, while holding other parameters fixed.

function of his strategy (see the online Appendix). This nonlinearity remains even if $F$, the electoral strength function, is linear.

37 From Proposition 1, we know $\pi_{\text {norev }}^{*} \leq 1-p$; from Proposition 2, we know $\pi_{\text {pass }}^{*}=\pi_{\text {norev }}^{*}$. Thus, $\pi_{\text {pass }}^{*} \leq 1-p$.
We then use computational methods to solve for the model's equilibria over a discrete grid in $\gamma-q$ space. For instance, consider the leftmost panel in Figure 2. On the horizontal axis, we vary $\gamma$, and on the vertical axis, we vary $q$. The shaded region of this panel identifies those values of $\gamma$ and $q$ for which passive equilibria exist. The center and right panels do the same for strict and active equilibria, respectively. Consistent with Proposition 4 and the intuitions from our partial equilibrium analysis (Remark 2), if we fix $\gamma$, then a high probability of a competent Leader $(q)$ facilitates the existence of passive equilibria, whereas small $q$ gives rise to strict equilibria. Likewise, and again consistent with the intuitions from Remark 2, if we fix $q$, then increasing judicial expertise $(\gamma)$ facilitates the existence of active equilibria.

Consideration of the general equilibrium case also reveals some potentially important features of the model that are not apparent in the partial-equilibrium analyses. First, the analysis suggests a possible explanation for the observation-often framed as a criticism-that judicial behavior in many domains is "unpredictable" (Rose-Ackerman 1988; Tushnet 1979). In our model, equilibrium judicial behavior may be unpredictable for two reasons. First, when the Judge uses an active review strategy her decision depends on her signal, which is not known in advance. Second, our general-equilibrium analysis implies a deeper, and potentially more interesting, form of unpredictability. As indicated by part (d) of Proposition 4, for some parameter values there is no equilibrium in which the Judge plays a pure strategy (active, passive, or strict). ${ }^{38}$ In such cases, one cannot be certain how the Judge will respond to a given signal because equilibrium behavior involves the Judge using a mixed strategy in which she randomizes her response to one of the two possible signals. This sort of uncertainty may be thought of as uncertainty with respect to the "standard of review" that the court will apply-a form of uncertainty often believed to be particularly problematic. Our model, however, suggests that this form of unpredictability may be the consequence of rational and strategic judicial behavior, rather than judicial carelessness or neglect of long-term consequences.

Our results also imply that for some parameter values, multiple equilibria may exist. For example, when $\bar{T}>\pi_{\text {act }}^{*}>\underline{T}>\pi_{\text {pass }}^{*}$, both active and passive review are sustainable in equilibrium. ${ }^{39}$ Whether the active or passive equilibrium is played when both exist depends on the equilibrium selection rule, which lies outside the scope of the model and may be thought of as an

\footnotetext{
$\overline{38 \text { Such would be the case, for example, if }} \bar{T} \geq 1>\pi_{\text {pass }}^{*}>\underline{T}>\pi_{a c t}^{*}$. In this case, if the Judge adopted an active strategy, posturing would be sufficiently low that a rational Judge would ignore her signal and always uphold the Leader's extraordinary proposal (i.e., use a passive strategy). If the Judge adopted a passive strategy, however, then posturing would be sufficiently frequent that a rational Judge would follow her signal (i.e., use an active strategy).

${ }^{39}$ This possibility is illustrated by Figure 2, in which the intersection between the set of parameters for which passive equilibria exist and the set of parameters for which active equilibria exist is nonempty.
} 


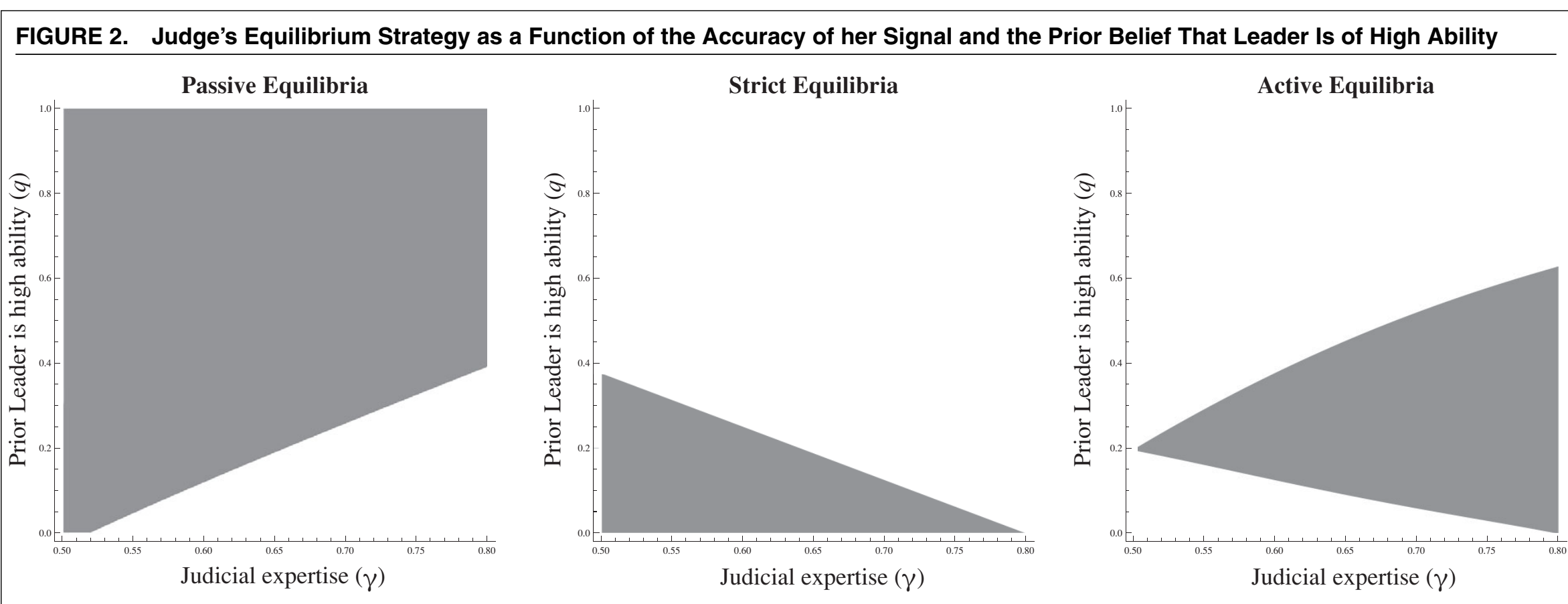

Notes: In each panel, we vary the level of judicial expertise $\gamma$ along the horizontal axis and the prior $q$ that the Leader is of high ability along the vertical axis, while holding fixed the other features of the model. The shaded region of the leftmost panel indicates those values of $\gamma$ and $q$ for which an equilibrium exists in which the Judge adopts a passive strategy. The shaded regions of the center and right panels indicate those values of $\gamma$ and $q$ for which an equilibrium exists in which the Judge adopts a strict strategy and an active strategy, respectively. For these simulations, we fix the prior $p$ that the state of the world $\omega=n$ and the weight $\alpha$ that the Leader attaches to policy. In addition, we fix the function $F$ that translates the Leader's reputation for being high ability into a probability of reelection. In particular, we set $p=0.8, \alpha=0.4$, and $F(\hat{q})=\hat{q}$. 
aspect—perhaps a manipulable aspect—of "legal culture."

Finally, this subsection's general equilibrium analysis suggests how the process of review itself-thus far taken to be exogenous-might be endogenized. As currently formulated, whenever the Leader proposes the extraordinary action, the extraordinary action is automatically reviewed by the Judge. However, over the region of the parameter space for which the unique equilibrium is passive, there is no incentive for the Judge to hear the case: The Judge knows that regardless of her signal, she will uphold the extraordinary action. Likewise, parties hurt by the extraordinary action might be hesitant to bring a case to the court when in this region of the parameter space because they know they will lose regardless of the evidence they present. In contrast, over the region of the parameter space in which equilibria are nonpassive, aggrieved parties have an incentive to bring cases, although this incentive may be attenuated by other factors, such as litigation costs. More generally, given that the Judge's incentive to adopt a nonpassive strategy depends on the rate of posturing, our model suggests that litigants (when deciding whether to bring a challenge) and courts (when deciding whether to hear a challenge) will consider the potential political calculations that influence the adoption of the policy in question. ${ }^{40}$

\section{WELFARE CONSEQUENCES OF JUDICIAL REVIEW}

We now consider the effect of judicial review on Voter welfare. In our setup, judicial review may affect Voter welfare through two distinct channels. First, judicial review affects the probability that the policy matches the state, which affects the Voter's current policy payoff. Second, judicial review affects the Voter's information regarding the incumbent Leader's type, which in turn affects the efficacy of elections as a device for selecting competent leaders. Through this channel, judicial review may affect the Voter's future payoff. We consider each effect in turn, remaining agnostic as to their relative importance.

\section{Policy Effects}

Consider first the effect of judicial review on the probability of a correct policy decision in the current period. The following proposition identifies how the form of judicial review (passive or nonpassive) affects the Voter's current policy payoff.

\section{Proposition 5.}

a. If judicial review induces a passive equilibrium, then judicial review has no effect on the Voter's expected current policy payoff.

b. If judicial review induces a nonpassive equilibrium in which posturing is lower than (equal to) that in

\footnotetext{
${ }^{40}$ Fully endogenizing the process of case generation and case selection is beyond the scope of this article.
}

the no review case, then judicial review improves (weakly improves) the Voter's expected current policy payoff.

c. If judicial review induces a nonpassive equilibrium in which posturing is greater than that in the no review case, then the effect of review on the Voter's expected current policy payoff is ambiguous.

Part (a) of Proposition 5 is straightforward: In a passive equilibrium, behavior is identical to the no review case, so judicial review has no effect. To understand parts (b) and (c), begin by recalling that when judicial review induces a nonpassive equilibrium, posturing may increase or decrease. However, holding the level of posturing fixed, the introduction of judicial review can never harm the Voter. This is because the Judge shares the Voter's policy preferences and strikes the extraordinary action only when doing so benefits the Voter in expectation (see Remark 1). Thus, nonpassive review has two distinct effects on the Voter's expected policy payoff. First, nonpassive judicial review changes the probability that the low-ability Leader will erroneously propose the extraordinary action in the normal state; second, nonpassive judicial review will correct some of these erroneous decisions by striking them down. ${ }^{41}$ If judicial review decreases posturing, then both of these effects cut in the same direction, leading to an unambiguous increase in the Voter's expected policy payoff [part (b)]. If, however, judicial review increases posturing, these effects cut in opposite directions, making the net effect of review on the Voter's current policy payoff unclear [part (c)]. ${ }^{42}$ Figure 3 extends the example used in Figure 2, contrasting the Voter's current policy payoff with and without judicial review. Note, in particular, the rightmost panel. The black region of this panel indicates those values of $\gamma$ and $q$ for which the Voter's current policy payoff is strictly lower with review. For such parameters, the level of posturing without review is not low enough to induce the Judge to employ a passive strategy; yet, nonpassive review exacerbates posturing to such an extent that the Voter fails to benefit from the Judge's expertise.

Proposition 5, together with Figure 3, provides some support and some challenges for both defenders and critics of judicial review. On the one hand, it is possible in our model for judicial review to worsen Voter

\footnotetext{
${ }^{41}$ Of course, the Judge will also erroneously strike down some justified extraordinary proposals; however, in equilibrium, the expected benefits of correct reversals outweigh the expected costs of erroneous reversals.

${ }^{42}$ For example, suppose judicial review induces an active equilibrium in which $\pi_{a c t}^{*}>\pi_{\text {norev }}^{*}$. Whether judicial review increases or decreases the Voter's current policy payoff in this instance turns on whether judicial review creates more instances of unjustified extraordinary action than it corrects, or corrects more than it creates. Alternatively, consider the case in which judicial review induces a strict equilibrium in which $\pi_{\text {strict }}^{*}>\pi_{\text {norev }}^{*}$. In a strict equilibrium, the final policy is always $n$. The cost of strict review is that the Voter no longer benefits from the high-ability Leader's expertise. The benefit is that the Voter no longer suffers from the low-ability Leader erroneously proposing $a=x$ when $\omega=n$. Whether the Voter benefits when review induces a strict equilibrium thus depends on the relative magnitude of these costs and benefits.
} 
FIGURE 3. Effect of Judicial Review on Voter's Current Policy Payoff

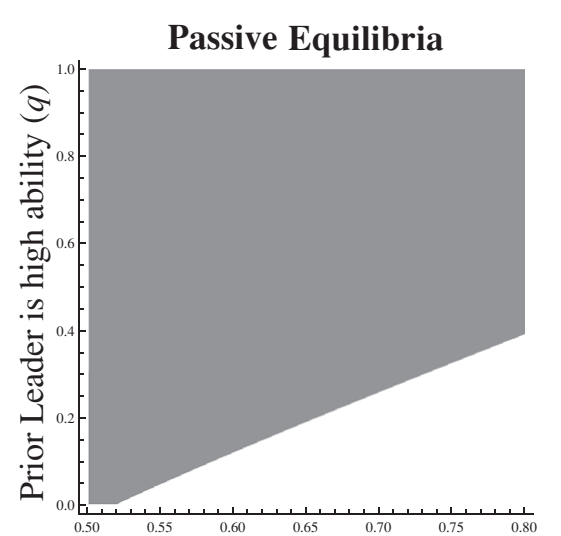

Judicial expertise $(\gamma)$

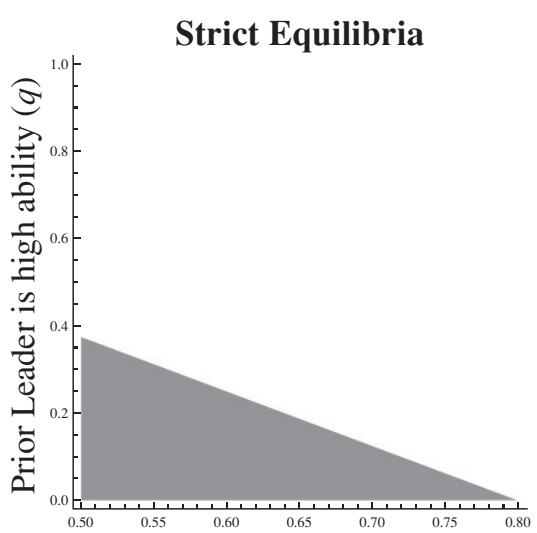

Judicial expertise $(\gamma)$

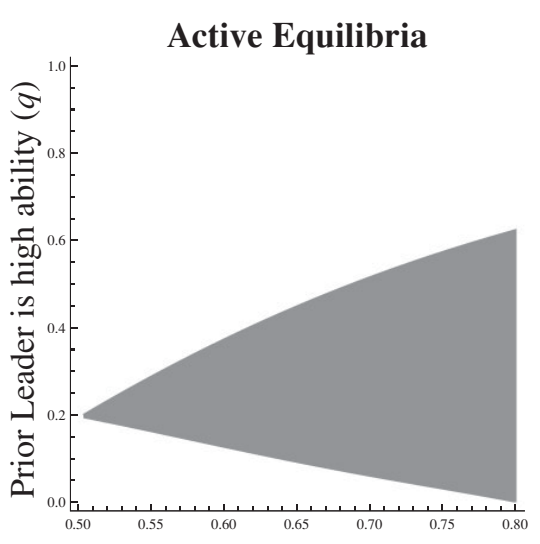

Judicial expertise $(\gamma)$

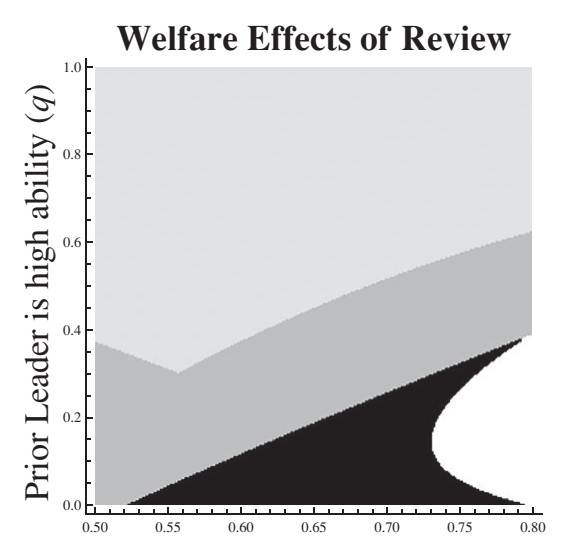

Judicial expertise $(\gamma)$

Notes: In each panel, we vary the level of judicial expertise $\gamma$ along the horizontal axis and the prior $q$ that the Leader is of high ability along the vertical axis, while holding fixed the other features of the model. The rightmost panel indicates the effect of review on the Voter's expected current policy payoff:

- The Voter is strictly worse off with review in the black region.

- The Voter is weakly worse off with review in the dark grey region (i.e., in this region, there exists a passive equilibrium and a nonpassive equilibrium, with the latter giving the

Voter a strictly lower expected current policy payoff than that with no review)

- The Voter's expected current policy payoff is the same with and without review in the light grey region.

- The Voter is strictly better off with review in the white region.

For these simulations, we fix the prior $p$ that the state of the world $\omega=n$ and the weight $\alpha$ that the Leader attaches to policy. In addition, we fix the function $F$ that translates the Leader's reputation for being high ability into a probability of reelection. In particular, we set $p=0.8, \alpha=0.4$, and $F(\hat{q})=\hat{q}$. 
welfare, despite the fact that the Judge in our model shares the Voter's state-contingent policy preferences. So, judicial bias is not a necessary condition for judicial review to have adverse effects on democratic performance: Judicial review may cause a large increase in posturing (most likely through a strong bailout effect) that overwhelms whatever benefits may accrue from judicial correction of erroneous decisions. This suggests a potentially serious problem with judicial review that defenders of the institution must take seriously. On the other hand, our analysis also highlights important limits to this "judicial overhang" concern. Increased posturing is not an inevitable consequence of judicial review-indeed, with a sufficiently strong legitimation effect, judicial review can reduce posturing, turning the judicial overhang argument on its head. Moreover, even if judicial review does increase posturing, it may correct enough erroneous policy decisions that the net impact on the Voter's expected current policy payoff is positive.

We conclude our analysis of judicial review's effects on the Voter's current payoff by considering how the Leader's electoral ambition (inversely measured by $\alpha$ ), the probability of a competent Leader $(q)$, and the ability of the Judge $(\gamma)$ jointly affect the desirability of judicial review:

\section{Proposition 6.}

a. Suppose $q \in\left(\frac{p-\gamma}{p}, \frac{p+\gamma-1}{p}\right)$ (i.e., the probability the Leader is of high ability is neither too small nor too large) and the electoral strength function $F$ is concave. Then judicial review strictly increases the Voter's current policy payoff provided that $\alpha$ is sufficiently small (i.e., the Leader's electoral ambition is strong enough). ${ }^{43}$

b. Suppose $\alpha \geq \bar{\alpha}$ (i.e., the Leader's electoral ambition is sufficiently weak). ${ }^{44}$ Then review can never increase the Voter's current policy payoff. Moreover, when $q \leq \frac{p-\gamma}{p}$ (i.e., the probability the Leader is of high ability is small enough), there exists a strict equilibrium in which the Voter's current policy payoff is strictly less than that with no review.

Part (a) establishes that when the Leader's electoral ambition is relatively large, conditions exist under which judicial review strictly benefits the Voter, whereas part (b) establishes that when the Leader's electoral ambition is relatively weak, the Voter can never benefit from review and, in some instances, can be harmed. The intuition for part (a) is as follows: The concavity of $F$ ensures that the legitimation effect dampens the low-ability Leader's electoral incentive to propose $a=x$. Thus, as long as the bailout effect is sufficiently small-as will be the case when the

\footnotetext{
${ }^{43}$ In addition, one can show that if $F$ is concave and $q \geq \frac{p+\gamma-1}{p}$, then the unique equilibrium is passive and review has no effect on the Voter's current policy payoff, regardless of $\alpha$.

${ }^{44}$ Recall from Proposition 1 that $\bar{\alpha} \equiv \frac{F(1)-F\left(\frac{p q}{p q+(1-q)}\right)}{2 p-1+F(1)-F\left(\frac{p q}{p q+(1-q)}\right)}$.
}

Leader's electoral ambition is strong-active review will decrease posturing and thus increase the Voter's current policy payoff relative to the case of no review. The requirement that $q \in\left(\frac{p-\gamma}{p}, \frac{p+\gamma-1}{p}\right)$ ensures that in any equilibrium the Judge both upholds and overrules the Leader with positive probability, so the legitimation effect of review is indeed operative. The intuition for part (b) is a bit more straightforward: When electoral ambition is weak, the low-ability Leader is a faithful agent of the Voter, so there is nothing to be gained from judicial review. However, the supposition in part (b) that $q \leq \frac{p-\gamma}{p}$ ensures the existence of strict equilibria, which, if induced by review, result in the Voter losing the benefit of the high-ability Leader's expertise. Thus, when electoral ambition is low, the Voter is better off with no review if review induces a strict equilibrium. Interestingly, part (b) points to the possibility that review can be harmful even when it is likely that the Leader is incompetent ( $q$ low). Notice that this is the case in Figure 3, where review is harmful for low values of $q$, but not for high values of $q .{ }^{45}$

\section{Electoral Selection Effects}

It is also important to consider how judicial review affects the efficacy of the electoral process in selecting competent Leaders, which affects the Voter's longterm welfare. Because we do not model future periods explicitly, we cannot provide a fully microfounded analysis of how judicial review affects future welfare. That said, our analysis permits the following observations: Most straightforward, if judicial review induces a passive equilibrium, judicial review has no effect on Voter learning. If judicial review induces a strict equilibrium, then Voter learning is never better than in the no review case. If there is no review, then the Voter learns nothing from the Judge, but can at least learn something from the Leader's action (provided $\alpha>0$ ). Under strict review, there is no helpful judicial signal, and the competent and incompetent Leaders choose the extraordinary action with identical probabilities, making the Leader's action uninformative. If judicial review induces an equilibrium in which the Judge sometimes follows her signal, then the result is more complicated because such judicial review can affect Voter learning via two distinct channels. First, when the Judge follows her signal, then this conveys additional information to the Voter; second, by changing the level of posturing, judicial review affects the

\footnotetext{
45 Proposition 6 might be taken as suggesting that judicial review is valuable if (but only if) electoral ambition is sufficiently strong, and that the case for judicial review strengthens as $\alpha$ decreases. However, there is no general relationship between the level of electoral ambition and the effect of judicial review on the Voter's current policy payoff. Examples exist in which increasing electoral ambition increases the benefits of review, but examples also exist in which increasing electoral ambition decreases the benefits of review (see the online Appendix). Thus, beyond the conditions established in Proposition 6, we cannot offer simple policy prescriptions linking electoral considerations (e.g., whether a politician is facing an imminent election) to the desirability of judicial review.
} 
Voter's ability to draw inferences directly from the Leader's action. If review has a minimal effect on the low-ability Leader's behavior, then judicial review increases Voter learning; however, if judicial review has a substantial effect on the Leader's behavior, then Voter learning may be better or worse than in the no review case.

It is important to emphasize that it is not necessarily the case that if judicial review improves the Voter's expected current policy payoff, it also improves Voter learning (or vice versa). Although these effects will sometimes cut in the same direction-favorable or unfavorable to judicial review-it is possible to construct scenarios in which they cut in opposite directions. ${ }^{46}$ Therefore, institutional designers interested in assessing the value of judicial review as an institution must be attentive both to how judicial review affects policy outcomes and to how it affects the efficacy of the electoral process in selecting high-quality political leaders. The former consideration is familiar. The latter, however, is often overlooked.

\section{Additional Implications}

The fact that the Judge in our model is rational and cares about getting the policy right, coupled with the fact for certain parameters judicial review leads to worse expected policy outcomes, has intriguing implications for our understanding of "justiciability" doctrines (standing, political question, etc.). While there are several plausible explanations for why judges would devise doctrines to limit their ability to hear certain cases, including the interests in reducing workload, avoiding controversy, pursuing substantive objectives surreptitiously, and controlling lower courts (e.g., Ho and Ross 2010; Pierce 1999). Our analysis suggests another possibility. Consider a situation in which judicial review would worsen the Voter's current expected policy payoff. To fix ideas, suppose that introducing judicial review induces an active equilibrium in which judicial screening does not offset the increased frequency with which the low-ability Leader proposes extraordinary action. Because the Judge shares the Voter's policy preferences, it follows that the Judge herself is worse off than she would be without judicial review. This does not mean the Judge is behaving irrationally in using the active strategy — given a high level of posturing, the

\footnotetext{
${ }_{46}$ For instance, a scenario in which judicial review enhances the Voter's current policy payoff, yet hinders Voter learning, is the following: fix $\alpha=0.1, q=0.2, p=0.8, F(\hat{q})=\hat{q}$, and $\gamma=0.6$. Then, without review, $\pi_{\text {norev }}^{*} \approx 0.1451$. With review, the unique equilibrium is strict, where $\pi_{\text {strict }}^{*}=0.2$. Although Voter learning is lower with review, the Voter's current policy payoff is higher. Specifically, the Voter's current policy payoff with review is 0.8 , whereas without review it is approximately 0.7703 .
}

Judge is better off following her signal. However, if the Judge could commit to uphold the Leader's proposal in all cases, posturing would decrease, and the Judge would be better off from an ex ante perspective. Whether such a commitment could ever be credible is a legitimate question, but one might plausibly interpret certain justiciability doctrines as judicial attempts to achieve such commitment.

Our model also helps illuminate debates concerning the value of judicial competence (higher $\gamma$ ). A natural conjecture is that if judicial review exists, the Voter would always be better off with a more competent Judge. Our model shows that this is not necessarily the case. As $\gamma$ increases, nonpassive review becomes more attractive to the Judge relative to passive review. However, when the Judge employs a nonpassive strategy, the policy cost to the low-ability Leader from proposing $a=x$ is lower. Thus, increasing the Judge's competence $\gamma$ can increase the rate at which the low-ability Leader erroneously proposes $a=x$ when $\omega=n$. If this effect is large enough, then increasing $\gamma$ can reduce the Voter's current policy payoff, despite the fact that the Judge has better information on which to base her rulings. ${ }^{47}$ This observation has implications for a variety of reform proposals that are intended to improve the quality of judicial review by, for example, facilitating judicial specialization (Jordan 1981), selecting more judges with decision-relevant expertise (Vermeule 2007), facilitating judicial acquisition of outside expert advice (Schauer 2001), and reorienting legal scholarship to provide more information about the pragmatic consequences of judicial decisions (Posner 1998). If reforms along these lines increase $\gamma$, then the impact on the quality of final policy decisions might well be desirable in many cases. However, if these reforms induce a formerly deferential judge to become active, then they may substantially increase posturing, making the Voter worse off.

\section{CONCLUSION}

Using a formal political agency model, we assess judicial review as a response to the concern that lowability leaders may "posture" by taking bold but illadvised policy initiatives in order to project a false image of competence. Our analysis, although limited in scope, generates a number of potentially useful insights about the relationship between judicial review and democratic performance. For instance, we show that judicial review may increase or decrease this sort of posturing, depending on the relative strength of the "bailout" and "legitimation" effects of judicial review, and that rational (and unbiased) judges will only engage in active review if the level of posturing

\footnotetext{
${ }^{47}$ An example in which increasing $\gamma$ reduces the Voter's current policy payoff is the following: fix $\alpha=0.2, q=0.5, p=0.8$, and $F(\hat{q})=\hat{q}$. When $\gamma=0.501$, the unique equilibrium is passive, $\pi_{\text {pass }}^{*} \approx 0.1195$, and the Voter's current policy payoff is approximately 0.8642 . In contrast, when $\gamma=0.701$, the unique equilibrium is active, $\pi_{\text {act }}^{*} \approx 0.1517$, and the Voter's current policy payoff is approximately 0.8626 .
} 
is high enough but not too high. Our analysis also produces a number of sometimes surprising comparative statics predictions, including the finding that increasing judicial ability may sometimes decrease rather than increase the desirability of judicial review. More generally, we derive conditions under which judicial review may improve or worsen voter welfare through a direct impact on policy outcomes and through an indirect impact on electoral sorting.

Our analysis also predicts and provides a rationalist explanation for a number of phenomena often associated with real world judicial systems, including judicial deference, legal unpredictability, and judicially created limits on the courts' own jurisdiction. Thus, our analysis is consistent with a recent trend in the literature that seeks to enrich the dialogue between formal political economy and traditional legal scholarship by illustrating how long-standing debates about controversial features of the legal system, including some thought to be "internal" to legal doctrine, might be illuminated by formal analysis of judges' strategic interaction with other actors (e.g., Bueno de Mesquita and Stephenson 2002; Lax n.d.)

Beyond these contributions, the larger objective of this article is to help lay the groundwork for a research program that would rigorously analyze the effect of judicial review on democratic performance in a political agency framework. Although we analyze judicial review as a response to one particular sort of political agency problem-posturing-future work might examine judicial review as a possible response to other pathologies that may arise, including the incentive of elected leaders to "pander" by selecting popular policies, or to adopt policies that adversely affect certain vulnerable minorities or are overly responsive to other minorities ("special interests"). Future work might also incorporate certain important concerns about judicial review this article has bracketed, such as judicial bias. More generally, the framework we develop here, when combined with the emerging literature on separationof-powers between elected branches of government (e.g., Fox and Van Weelden 2010; Persson, Roland, and Tabellini 1997; Stephenson and Nzelibe 2010), may facilitate direct comparisons between judicial and political oversight of government decision making-a crucial issue in contemporary legal and policy debates, which the extant political economy literature has not fully engaged.

\section{REFERENCES}

Ashworth, Scott, and Kenneth W. Shotts. 2010. "Does Informative Media Commentary Reduce Politicians' Incentives to Pander?" Journal of Public Economics 94 (11-12): 838-47.

Austen-Smith, David, and Jeffrey Banks. 1989. "Electoral Accountability and Incumbency." In Models of Strategic Choice in Politics, ed. Peter C. Ordeshook. Ann Arbor: University of Michigan Press, $121-48$.

Avery, Christopher N., and Judith A. Chevalier. 1999. "Herding over the Career." Economic Letters 63 (3): 327-33.

Bueno de Mesquita, Ethan, and Matthew C. Stephenson. 2002. "Informative Precedent and Intrajudicial Communication." American Political Science Review 96: 755-66.
Canes-Wrone, Brandice, Michael C. Herron, and Kenneth W. Shotts. 2001. "Leadership and Pandering: An Equilibrium Theory of Executive Policymaking." American Journal of Political Science 45 (3): 532-50.

Clawson, Rosalee A., Elizabeth R. Kegler, and Eric N. Waltenburg. 2001. "The Legitimacy-conferring Authority of the U.S. Supreme Court: An Experimental Design." American Politics Research 29 (6): 566-91

Cole, David. 2008. "No Reason to Believe: Radical Skepticism, Emergency Power, and Constitutional Constraint." University of Chicago Law Review 75: 1329-64.

Dworkin, Ronald. 1985. A Matter of Principle. Cambridge, MA: Harvard University Press.

Eisgruber, Christopher L. 2001. Constitutional Self-government. Cambridge, MA: Harvard University Press.

Elhauge, Einer R. 1991. "Does Interest Group Theory Justify More Instrusive Judicial Review?" Yale Law Journal 101: 31-110.

Ely, John Hart. 1980. Democracy and Distrust: A Theory of Judicial Review. Cambridge, MA: Harvard University Press.

Fearon, James D. 1999. "Electoral Accountability and the Control of Politicians: Selecting Good Types versus Sanctioning Poor Performance." In Democracy, Accountability, and Representation, eds. A. Przeworski, S. C. Stokes, and B. Manin. New York: Cambridge University Press, 55-97.

Ferejohn, John, and Charles R. Shipan. 1990. "Congressional InŠuence on Bureaucracy." Journal of Law, Economics, and Organization 6 (Special Issue): 1-20.

Fox, Justin. 2007. "Government Transparency and Policymaking." Public Choice 131: 23-44.

Fox, Justin, and Matthew C. Stephension. 2009. "Judicial Review and Democratic Failure." Yale University. Unpublished Manuscript.

Fox, Justin, and Richard Van Weelden. 2010. "Partisanship and the Effectiveness of Oversight." Journal of Public Economics 94 (910): 674-87.

Friedman, Barry. 2002. "The Birth of an Academic Obsession: The History of the Countermajoritarian Difficulty, Part Five." Yale Law Journal 112: 153-259.

Friedman, Barry. 2009. The Will of the People: How Public Opinion Has Influenced the Supreme Court and Shaped the Meaning of the Constitution. New York: Farrar, Straus and Giroux.

Hirschl, Ran. 2000. “The Political Origins of Judicial Empowerment through Constitutionalization: Lessons from Four Constitutional Revolutions." Law and Social Inquiry 25 (1): 91-152.

Hirschl, Ran. 2004. Towards Juristocracy: The Origins and Consequences of the New Constitutionalism. Cambridge, MA: Harvard University Press.

Ho, Daniel E., and Erica L. Ross. 2010. "Did Liberal Justices Invent the Standing Doctrine? An Empirical Study of the Evolution of Standing, 1921-2006." Stanford Law Review 62: 59167.

Hoekstra, Valerie J., and Jeffrey A. Segal. 1996. "The Shepherding of Local Public Opinion: The Supreme Court and Lamb's Chapel." Journal of Politics 58 (4): 1079-1102.

Issacharoff, Samuel, and Richard H. Pildes. 1998. "Politics as Markets: Partisan Lockups of the Democratic Process." Stanford Law Review 50: 643-717.

Jordan, Ellen R. 1981. "Specialized Courts: A Choice.” Northwestern University Law Review 76 (5): 745-85.

Komesar, Neil K. 1994. Imperfect Alternatives: Choosing Institutions in Law, Economics, and Public Policy. Chicago: University of Chicago Press.

Kuran, Timur, and Cass R. Sunstein. 1999. "Availability Cascades and Risk Regulation.” Stanford Law Review 51: 683-768.

Lax, Jeffrey R. N.d. "The New Judicial Politics of Legal Doctrine." Annual Review of Political Sceince. Forthcoming

Levy, Gilat. 2004. "Anti-herding and Strategic Consultation.” European Economic Review 48 (3): 503-25.

Maskin, Eric, and Jean Tirole. 2004. "The Politician and the Judge: Accountability in Government." American Economic Review 94: 1034-54.

Persson, Torsten, Gerard Roland, and Guido Tabellini. 1997. "Separation of Powers and Political Accountability." Quarterly Journal of Economics 112: 310-27.

Pierce, Richard J., Jr. 1991. "The Unintended Effects of Judicial Review of Agency Rules: How Federal Courts Have Contributed 
to the Electricity Crisis of the 1990s." Administrative Law Review 43: 7-29.

Pierce, Richard J., Jr. 1999. "Is Standing Law or Politics?” North Carolina Law Review 77: 1741-89.

Posner, Eric A. 2008. "Does Political Bias in the Judiciary Matter? Implications of Judicial Bias Studies for Legal and Constitutional Reform." University of Chicago Law Review 75: 853-83.

Posner, Richard A. 1998. "Against Constitutional Theory." New York University Law Review 73: 1-22.

Prat, Andrea. 2005. "The Wrong Kind of Transparency." American Economic Review 95 (3): 862-77.

Prendergast, Canice. 1993. "A Theory of 'Yes Men." American Economic Review 83 (4): 757-70.

Prendergast, Canice, and Lars Stole. 1996. "Impetuous Youngsters and Jaded Old-timers: Acquiring a Reputation for Learning." Journal of Political Economy 104: 1105-34.

Ramirez, Steven A. 2007. "The Special Interest Race to CEO Primacy and the End of Corporate Governance Law." Delaware Journal of Corporate Law 32: 345-92.

Rogers, James R. 1999. "Legislative Incentives and Two-tiered Judicial Review: A Game Theoretic Reading of Carolene Products Footnote Four.” American Journal of Political Science 43 (4): 10961121.

Rogers, James R. 2001. "Information and Judicial Review: A Signaling Game of Legislative-Judicial Interaction." American Journal of Political Science 45 (1): 84-99.

Rogers, James R. 2009. "Casting the Gimlet Eye on Judicial Review: Can Judicial Review Be Democratically Debilitating?" Texas A\&M University. Unpublished Manuscript.

Rogers, James R., and Georg Vanberg. 2007. "Resurrecting Lochner: A Defense of Unprincipled Judicial Activism." Journal of Law, Economics, and Organization 23 (2): 442-68.

Romano, Roberta. 2005. "The Sarbanes-Oxley Act and the Making of Quack Corporate Governance." Yale Law Journal 114: 15211611.

Rose-Ackerman, Susan. 1988. "Against Ad Hocery: A Comment on Michelman." Columbia Law Review 88: 1697-1711.

Salzberger, Eli M. 1993. "A Positive Analysis of the Doctrine of Separation of Powers, or: Why Do We Have an Independent Judiciary?" International Review of Law and Economics 13: 349-79.

Schauer, Frederick. 2000. "Incentives, Reputation, and the Inglorious Determinants of Judicial Behavior." University of Cincinnatti Law Review 68: 615-36.
Schauer, Frederick. 2001. "The Dilemma of Ignorance: PGA Tour, Inc. v. Casey Martin." Supreme Court Review 2001: 267-97.

Schauer, Frederick. 2006. "Do Cases Make Bad Law?" University of Chicago Law Review 73: 883-918.

Sherwin, Emily. 2006. "Judges as Rulemakers." University of Chicago Law Review 73: 919-31.

Stephenson, Matthew C. 2008. "The Price of Public Action: Constitutional Doctrine and the Judicial Manipulation of Legislative Enactment Costs." Yale Law Journal 118 (1): 2-62.

Stephenson, Matthew C. 2011. "Information Acquisition and Institutional Design." Harvard Law Review 124 (6): 1422-83.

Stephenson, Matthew C., and Jide O. Nzelibe. 2010. "Political Accountability under Alternative Institutional Regimes." Journal of Theoretical Politics 22: 139-67.

Sunstein, Cass R. 1984. "Naked Preferences and the Constitution." Columbia Law Review 84: 1689-1732.

Sunstein, Cass R. 1985. "Interest Groups in American Public Law." Stanford Law Review 38: 29-87.

Swire, Peter P. 2004. "The System of Foreign Intelligence Surveillance Law." George Washington Law Review 72: 1306-72.

Thayer, James Bradley. 1893. "The Origin and Scope of the American Doctrine of Constitutional Law." Harvard Law Review 7 (3): 12956.

Tsebelis, George. 2002. Veto Players: How Political Institutions Work. Princeton, NJ: Princeton University Press.

Tullock, Gordon. 1979. "Public Decisions as Public Goods." Journal of Political Economy 79: 913-18.

Tushnet, Mark. 1979. "Rethinking the Dormant Commerce Clause." Wisconsin Law Review 1979: 125-65.

Tushnet, Mark. 1999. Taking the Constitution away from the Courts. Princeton, NJ: Princeton University Press.

Vermeule, Adrian. 2006. Judging under Uncertainty: An Institutional Theory of Legal Interpretation. Cambridge, MA: Harvard University Press.

Vermeule, Adrian. 2007. "Should We Have Lay Justices?" Stanford Law Review 59: 1569-1611.

Vermeule, Adrian. 2009. Law and the Limits of Reason. New York: Oxford University Press.

Waldron, Jeremy. 2006. "The Core of the Case against Judicial Review." Yale Law Journal 115: 1346-1406.

Young, Ernest A. 2000. "Constitutional Avoidance, Resistance Norms, and the Preservation of Judicial Review." Texas Law Review 78: 1549-1614. 